\title{
Evaluation of sexual dysfunction in Brazilian women with breast cancer: partial results
}

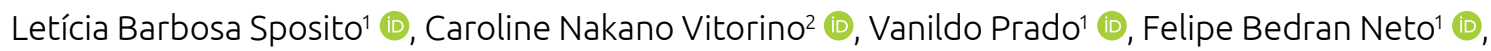

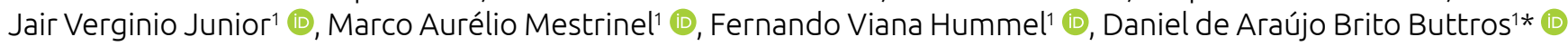

\section{ABSTRACT}

Objective: To assess the pattern of sexual performance in women treated for breast cancer. Methods: This is a cross-sectional study on women treated for breast cancer. Inclusion criteria: to have undergone the first-line therapy for cancer and the cancer not being classified as stage IV. Data on cancer were collected by the analysis of medical records. For the evaluation of sexual performance, women were submitted to individual interviews, with the application of the Quociente Sexual - Versão Feminina (QS-F) questionnaire. Sexual performance was classified as: bad, unfavorable, regular, good, and excellent. The diagnosis of sexual dysfunction was established to women with score $\leq 60$. For descriptive analyses, absolute (n) and relative (\%) frequencies were performed, and for the comparison between the quantitative variables the Student's t-test was used. Results: 31 women with a mean age of 55.2 years were included, $35 \%$ were classified as clinical stage II, $84 \%$ underwent conservative surgery, $65 \%$ underwent chemotherapy, and $80 \%$ used endocrinotherapy. Regarding sexual performance, $62 \%$ spontaneously think about sex, $35 \%$ are always interested in sex, and $51.7 \%$ have some degree of pain during intercourse. After calculating the score, it was concluded that $6.5 \%$ had bad sexual performance; $19.4 \%$, unfavorable; $19.4 \%$, regular; $41.9 \%$, good; and $12.8 \%$, excellent. The mean score was 58.7 points (standard deviation $=21.4$, median of 64 , minimum of 16 , and maximum of 90 points), and $45.2 \%$ of women were diagnosed with sexual dysfunction. The provided treatments and the length of follow-up did not have a significant correlation with sexual performance. Conclusion: Most women treated for breast cancer had sexual performance classified as "good and excellent," although a significant percentage had a diagnosis of sexual dysfunction.

KEYWORDS: breast neoplasms; sexuality; dyspareunia; quality of life.

\section{INTRODUCTION}

In recent decades, the number of patients who survive breast cancer has increased ${ }^{1}$. The results of this increase are partly due to the greater effectiveness of adjuvant treatments ${ }^{1}$. According to data from the National Cancer Institute (INCA), breast cancer is the leading cause of death due to cancer among women in Brazil $^{2}$. The survival rate for patients with this type of cancer is approximately $76 \%$ to $92 \%$ worldwide ${ }^{3}$, directly depending on initial staging and the tumor subtype.

Technological advances in the healthcare area have resulted in chronic conditions and increased patient survival ${ }^{4,5}$. In this context, oncology is highlighted, and the need for assessing and prioritizing the quality of life of oncologic patients arises ${ }^{4,6}$. According to the World Health Organization (WHO), quality of life is defined as: "The individual's perception of their position in life in the context of the culture and value systems in which they live and in relation to their goals, expectations, standards and concerns" ${ }^{\prime 2}$. Sexual health is directly related to quality of life and must be addressed with specialized approach ${ }^{1}$. Sexual dysfunction is frequent among women, and the prevalence rate ranges between $9 \%$ and $43 \%^{7}$.

Sexual health has been recently recognized as one of the areas of concern in patients who survive breast cancer and one of the aspects of care that is overlooked by healthcare professionals ${ }^{1}$.

Female sexual dysfunctions include abnormalities in sexual desire, arousal, lubrication, satisfaction, and dyspareunia, which is one of the most common complications in patients with breast cancer ${ }^{3}$.

${ }^{1}$ Centro Universitário Claretiano - Rio Claro (SP), Brazil.

2Santa Casa de Misericórdia de Rio Claro - Rio Claro (SP), Brazil.

*Corresponding author: danielbuttros@claretiano.edu.br

Conflict of interest: nothing to declare.

Received on: 05/08/2020 Accepted on: 09/14/2020 
Sexual dysfunctions among women treated for breast cancer are common, and most women have some degree of sexual dysfunction after undergoing treatment?

The etiology of female sexual dysfunctions is heterogeneous and multifactorial, with complex symptoms that may respond to multimodal therapies 8 .

The approach to sexual dysfunction requires knowledge on the part of healthcare professionals, and the treatment depends on the correct etiology identification.

The aim of this study was to assess the pattern of sexual performance in women treated for breast cancer.

\section{METHODS}

This is a cross-sectional clinical study. Inclusion criteria were as follows:

- to present histopathological diagnosis of breast cancer;

- to have undergone the first-line therapy for cancer (surgery, chemotherapy, and radiotherapy);

- to be classified in stages I, II, or III;

- to have been seen in medical services of the Brazilian Unified Health System;

- to have signed the informed consent form.

Sample size calculation was based on the study conducted by Jing et al. ${ }^{3}$, who found sexual dysfunction in $73.4 \%$ of women treated for breast cancer? ${ }^{7}$ Taking this frequency into consideration, with a $5 \%$ significance level and type II error of $10 \%$ (90\% test power), the need for evaluating at least 176 patients with breast cancer was estimated. This publication presents partial results of the current research.

Data on cancer, such as staging, treatment, and length of follow-up, were collected by analyzing medical records.

For evaluating sexual performance, women were submitted to individual interviews with the application of the Quociente Sexual - Versão Feminina (Female Sexual Quotient - QS-F) questionnaire $^{9}$ (Appendix 1) (all interviews were conducted by the same researcher - Sposito, LB).

The QS-F is composed of 10 objective questions, and each question scores from 0 to 5 , according to the answers: never (0), rarely (1), sometimes (2), often (3), usually (4), always (5). The result of the sum of the 10 answers must be multiplied by 2 , which results in a total index ranging from 0 to 100 . The seventh question must be differently addressed, that is, the value of the answer (from 0 to 5 ) must be subtracted from 5 in order to have the final score.

The value of the final sum indicates better sexual performance/satisfaction, namely:

- 82 - 100 points: good to excellent;

- $62-80$ points: regular to good;

- $42-60$ points: unfavorable to regular;
- $22-40$ points: bad to unfavorable;

- $0-20$ points: null to bad.

The diagnosis of sexual dysfunction was given to women with score $\leq 60$, considering that score $>60$ corresponds to normality 9 .

For the statistical study, a descriptive analysis of the data was performed using absolute (n) and relative (\%) frequencies, measures of central tendency (mean and median) and dispersion (standard deviation [SD], minimum and maximum values). For the comparison between the quantitative variables and the outcome "sexual life in the last six months" grouped into "good to excellent" and "regular to bad," the Student's t-test was used. In the association between qualitative predictor variables and the outcome, the Fisher's exact test was used. For statistical significance, $p<0.050$ was considered. Data were entered into an Excel spreadsheet and analyzed using the Statistical Package for the Social Sciences (SPSS) software, version 23.0 for Windows.

The study was submitted to and approved by the Research Ethics Committee, Plataforma Brasil/CAAE:02241618.1.0000.5381.

\section{RESULTS}

A total of 31 women diagnosed with breast cancer were evaluated. The mean age was 55.2 years $(\mathrm{SD}=11.1)$, with a median of 55 , ranging between 23 and 77 years.

Graph 1 shows the percentage distribution, and in absolute number, of the clinical stage of the study patients.

Table 1 shows that all women underwent surgery; $83.9 \%$ underwent conservative surgery; 96.8\%, radiotherapy; $80.7 \%$, endocrinotherapy; and $64.5 \%$, chemotherapy.

Table 2 describes all the questions of the QS-F. It is noteworthy that approximately $40 \%$ of women "never" tend to spontaneously think about sex, remember sex, or imagine themselves having sex. However, $35.5 \%$ are "always" interested in sex in such a way to willingly engage in intercourse. When asked if the degree of satisfaction with intercourse makes them want to have sex at other times,

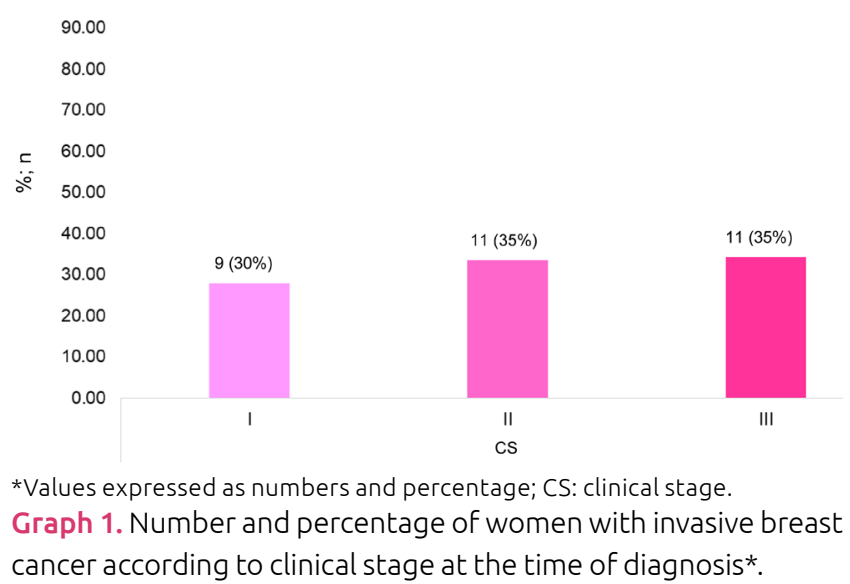


Table 1. Number and percentage of women with invasive breast cancer according to treatment*.

\begin{tabular}{l|c|c|c}
\multirow{2}{*}{ Variables } & Categories & $\mathbf{n}$ & $\%$ \\
\cline { 2 - 4 } Surgery & Mastectomy & 5 & 16.1 \\
\cline { 2 - 4 } & Conservative surgery & 26 & 83.9 \\
\hline \multirow{2}{*}{ Chemotherapy } & No & 11 & 35.5 \\
\cline { 2 - 4 } & Yes & 20 & 64.5 \\
\hline \multirow{2}{*}{ Endocrinotherapy } & No & 6 & 19.3 \\
\cline { 2 - 4 } & Yes & 25 & 80.7 \\
\hline \multirow{2}{*}{ Radiotherapy } & No & 30 & 3.2 \\
\cline { 2 - 4 } & Yes & 31 & 100.0 \\
\hline
\end{tabular}

*Values expressed as numbers and percentage.

Table 2. Number and percentage of women with invasive breast cancer according to questions of the Female Sexual Quotient questionnaire.

\begin{tabular}{|c|c|c|c|}
\hline Variables & Categories & $n$ & $\%$ \\
\hline \multirow{5}{*}{$\begin{array}{l}\text { Q1. Do you usually have } \\
\text { spontaneous thoughts } \\
\text { about sex, remember sex, or } \\
\text { imagine yourself having sex? }\end{array}$} & Never & 12 & 38.7 \\
\hline & Rarely & 5 & 16.1 \\
\hline & Sometimes & 6 & 19.4 \\
\hline & Often & 5 & 16.1 \\
\hline & Usually & 3 & 9.7 \\
\hline \multirow{6}{*}{$\begin{array}{l}\text { Q2. Are you interested } \\
\text { enough in sex to willingly } \\
\text { engage in intercourse? }\end{array}$} & Never & 6 & 19.4 \\
\hline & Rarely & 4 & 12.9 \\
\hline & Sometimes & 3 & 9.7 \\
\hline & Often & 5 & 16.1 \\
\hline & Usually & 2 & 6.5 \\
\hline & Always & 11 & 35.5 \\
\hline \multirow{6}{*}{$\begin{array}{l}\text { Q3. Does foreplay (caresses, } \\
\text { kisses, hugs, cuddles, etc.) } \\
\text { encourage you to continue } \\
\text { intercourse? }\end{array}$} & Never & 2 & 6.5 \\
\hline & Rarely & 4 & 12.9 \\
\hline & Sometimes & 2 & 6.5 \\
\hline & Often & 1 & 3.2 \\
\hline & Usually & 6 & 19.4 \\
\hline & Always & 16 & 51.6 \\
\hline \multirow{6}{*}{$\begin{array}{l}\text { Q4. Do you usually get } \\
\text { lubricated during intercourse? }\end{array}$} & Never & 9 & 29.0 \\
\hline & Rarely & 3 & 9.7 \\
\hline & Sometimes & 5 & 16.1 \\
\hline & Often & 1 & 3.2 \\
\hline & Usually & 3 & 9.7 \\
\hline & Always & 10 & 32.3 \\
\hline
\end{tabular}

Table 2. Continuation.

\begin{tabular}{|c|c|c|c|}
\hline Variables & Categories & $n$ & $\%$ \\
\hline \multirow{5}{*}{$\begin{array}{l}\text { Q5. During intercourse, } \\
\text { as your partner's arousal } \\
\text { increases, do you feel more } \\
\text { stimulated to have sex? }\end{array}$} & Never & 2 & 6.5 \\
\hline & Rarely & 4 & 12.9 \\
\hline & Sometimes & 3 & 9.7 \\
\hline & Usually & 3 & 9.7 \\
\hline & Always & 19 & 61.3 \\
\hline \multirow{5}{*}{$\begin{array}{l}\text { Q6. During intercourse, } \\
\text { do you relax the vagina } \\
\text { enough to facilitate penile } \\
\text { penetration? }\end{array}$} & Never & 5 & 16.1 \\
\hline & Rarely & 1 & 3.2 \\
\hline & Often & 3 & 9.7 \\
\hline & Usually & 3 & 9.7 \\
\hline & Always & 19 & 61.3 \\
\hline \multirow{6}{*}{$\begin{array}{l}\text { Q7. Do you usually feel pain } \\
\text { during intercourse when the } \\
\text { penis penetrates your vagina? }\end{array}$} & Never & 14 & 45.2 \\
\hline & Rarely & 1 & 3.2 \\
\hline & Sometimes & 3 & 9.7 \\
\hline & Often & 3 & 9.7 \\
\hline & Usually & 3 & 9.7 \\
\hline & Always & 7 & 22.6 \\
\hline \multirow{6}{*}{$\begin{array}{l}\text { Q8. Can you be engaged, } \\
\text { without getting } \\
\text { distracted (without losing } \\
\text { concentration), in and during } \\
\text { intercourse? }\end{array}$} & Never & 4 & 12.9 \\
\hline & Rarely & 2 & 6.5 \\
\hline & Sometimes & 4 & 12.9 \\
\hline & Often & 3 & 9.7 \\
\hline & Usually & 2 & 6.5 \\
\hline & Always & 16 & 51.6 \\
\hline \multirow{6}{*}{$\begin{array}{l}\text { Q9. Can you reach orgasm } \\
\text { (maximum pleasure) in the } \\
\text { intercourses you engage in? }\end{array}$} & Never & 6 & 19.4 \\
\hline & Rarely & 7 & 22.6 \\
\hline & Sometimes & 4 & 12.9 \\
\hline & Often & 2 & 6.5 \\
\hline & Usually & 1 & 3.2 \\
\hline & Always & 11 & 35.5 \\
\hline \multirow{6}{*}{$\begin{array}{l}\text { Q10. Does the degree of } \\
\text { satisfaction you feel from } \\
\text { intercourse make you desire } \\
\text { to have sex at other times, on } \\
\text { other days? }\end{array}$} & Never & 6 & 19.4 \\
\hline & Rarely & 4 & 12.9 \\
\hline & Sometimes & 3 & 9.7 \\
\hline & Often & 3 & 9.7 \\
\hline & Usually & 2 & 6.5 \\
\hline & Always & 13 & 41.9 \\
\hline \multicolumn{2}{|l|}{ Total } & 31 & 100.0 \\
\hline
\end{tabular}

*Values expressed as numbers and percentage; QS-F: Female Sexual Quotient questionnaire.

on other days, $41.9 \%$ of women answered "always." As for the general score (Graph 2), 41.9\% were classified as having regular to good sexual performance, and $12.9 \%$ as good to excellent. The mean score was 58.7 points ( $\mathrm{SD}=21.4$ ), median of 64 , minimum of 16 , and maximum of 90 points. Considering the concept of sexual dysfunction in women with scores $\geq 60,45.2 \%$ of women received this diagnosis. 


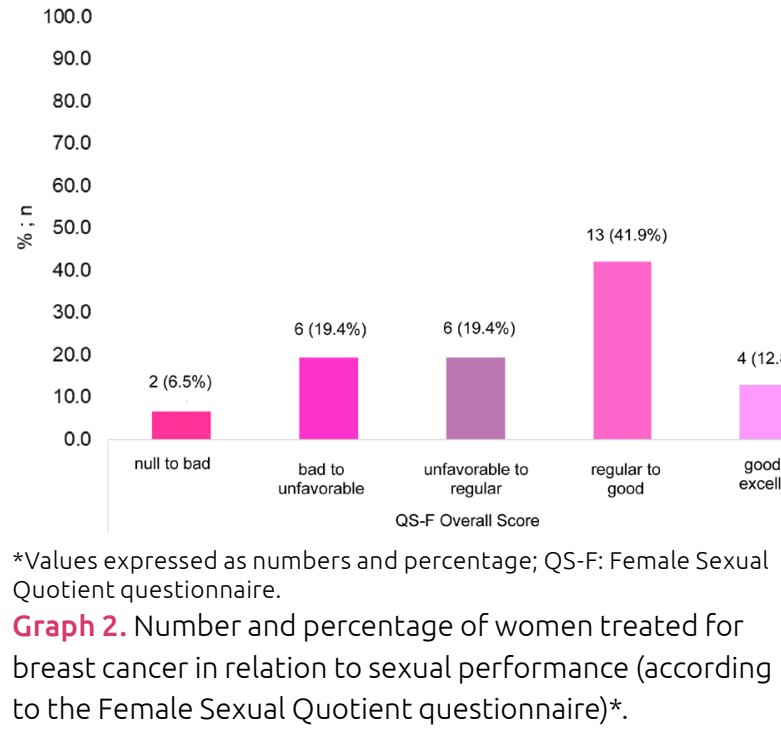

In the inferential analysis, the QS-F outcome variable was grouped into two groups: "good to excellent" (regular to good + good to excellent) and "regular to bad" (null to bad + bad to unfavorable + unfavorable to regular). There was no statistical difference between groups according to age $(p=0.311)$ and length of follow-up ( $p=653$ ) (values are presented in Table 3 ).

Table 4 demonstrates that there was no statistically significant association between the clinical stage and cancer treatments versus the classification of sexual life in the last six months.

\section{DISCUSSION}

This study demonstrated that most women treated for breast cancer (41.9\%) classified their sexual performance as "regular to good," according to the application of the QS-F questionnaire. A total of $38 \%$ of women classified the sexual performance as "bad to unfavorable" and "unfavorable to regular" (19.4\% each). The extreme ratings, "good to excellent" and "null to bad," were associated with $12.9 \%$ and $6.5 \%$ of women, respectively. The diagnosis of sexual dysfunction was given to $45.2 \%$ of women, demonstrating that strategies for approaching and treating this population must be taken into account.

The QS-F was developed in the Programa de Estudos em Sexualidade (Program of Studies on Sexuality - ProSex) of the Psychiatry Institute of Hospital das Clínicas, Medical School - University of São Paulo9. Validation was performed by comparing the mean scores of women with sexual dysfunction and others who did not have the problem. Both groups were categorized as for sociodemographic characteristics. The QS-F comprises ten objective questions and classifies the pattern of sexual dysfunction as: bad, unfavorable, regular, good, and excellent ${ }^{9}$. This questionnaire can be interpreted in terms of total score,
Table 3. Comparison between the variable age and length of follow-up versus Female Sexual Quotient questionnaire*.

\begin{tabular}{|c|c|c|c|c|c|}
\hline Variable & $\begin{array}{l}\text { Categories } \\
\text { (QS-F) }\end{array}$ & $n$ & Mean & SD & p-value \\
\hline \multirow{2}{*}{ Age } & $\begin{array}{l}\text { good to } \\
\text { excellent }\end{array}$ & 17 & 53.294 & 12.7317 & \multirow{2}{*}{0.311} \\
\hline & $\begin{array}{l}\text { regular to } \\
\text { bad }\end{array}$ & 14 & 57.429 & 8.7417 & \\
\hline \multirow{2}{*}{$\begin{array}{l}\text { Length of } \\
\text { follow-up }\end{array}$} & $\begin{array}{l}\text { good to } \\
\text { excellent }\end{array}$ & 17 & 4.294 & 2.9742 & \multirow{2}{*}{0.653} \\
\hline & $\begin{array}{l}\text { regular to } \\
\text { bad }\end{array}$ & 14 & 4.714 & 1.9386 & \\
\hline
\end{tabular}

*Values expressed as numbers, mean, standard deviation (SD), and p-value; QS-F: Female Sexual Quotient questionnaire.

Table 4. Association between predictor variables and the outcome of the Female Sexual Quotient questionnaire*.

\begin{tabular}{|c|c|c|c|c|c|c|}
\hline \multirow{3}{*}{ Variables } & \multirow{3}{*}{ Categories } & \multicolumn{5}{|c|}{ QS-F } \\
\hline & & \multicolumn{2}{|c|}{$\begin{array}{l}\text { Good to } \\
\text { excellent }\end{array}$} & \multicolumn{2}{|c|}{$\begin{array}{c}\text { Regular } \\
\text { to bad }\end{array}$} & \multirow{2}{*}{ p-value } \\
\hline & & n & $\%$ & n & $\%$ & \\
\hline \multirow{3}{*}{ CS } & I & 5 & 29.4 & 4 & 28.6 & \multirow{3}{*}{0.899} \\
\hline & II & 5 & 29.4 & 6 & 42.9 & \\
\hline & III & 7 & 41.2 & 4 & 28.6 & \\
\hline \multirow{2}{*}{ Surgery } & Mastectomy & 2 & 11.8 & 3 & 21.4 & \multirow{2}{*}{0.636} \\
\hline & Quadrantectomy & 15 & 88.2 & 11 & 78.6 & \\
\hline \multirow{2}{*}{ CT } & No & 5 & 29.4 & 6 & 42.9 & \multirow{2}{*}{0.477} \\
\hline & Yes & 12 & 70.6 & 8 & 57.1 & \\
\hline \multirow{2}{*}{ HT } & No & 2 & 11.8 & 4 & 28.6 & \multirow{2}{*}{0.370} \\
\hline & Yes & 15 & 88.2 & 10 & 71.4 & \\
\hline \multirow{2}{*}{ RT } & No & 1 & 5.9 & 0 & 0.0 & \multirow{2}{*}{1.000} \\
\hline & Yes & 16 & 94.1 & 14 & 100.0 & \\
\hline \multicolumn{2}{|l|}{ Total } & 17 & 100.0 & 14 & 100.0 & \\
\hline
\end{tabular}

*Values expressed as numbers and percentage; CS: clinical stage; CT: chemotherapy; HT: hormone therapy; RT: radiotherapy; QS-F: Female Sexual Quotient questionnaire.

assessing the general quality of women's sexual performance/ satisfaction. Conversely, for comprising all phases of the sexual response cycle, in addition to associated domains, the instrument also indicates the difficulties of each patient according to specific aspects of the responses. Therefore, through ten selfadministered questions, the QS-F assesses all phases of the sexual response cycle, including other domains, namely: sexual desire and interest (questions 1, 2, and 8); foreplay (question 3); personal arousal and attunement with the partner (questions 4 and 5); comfort (questions 6 and 7); orgasm and satisfaction (questions 9 and 10). Low scores for questions 1, 2, and 8 mean 
that sexual desire is not enough for the woman to be interested and satisfied with the intercourse. Questions 3, 4, 5, and 6 assess different aspects of the female arousal phase during intercourse (response to foreplay, lubrication, attunement with the partner, and reception to penetration). Low scores for these questions indicate little capacity of engagement and decreased response to sexual stimulation. A high score for question 7 confirms the presence of pain in the relationship. Difficulty with orgasm and little or no satisfaction with sex are evidenced by low scores for questions 9 and $10^{9}$.

Considering the different phases of the sexual response cycle addressed by the QS-F, the present study demonstrated that, according to the concept of sexual desire and interest, $38.7 \%$ of women responded they never think about sex. In comparison with general data of the Brazilian population, such value is much higher than $8.2 \%$ of women who have no interest in sex'. On the other hand, $58.1 \%$ of women always, usually, or often willingly engage in intercourses, and $51.6 \%$ are always engaged in intercourse without being distracted. This fact demonstrates that, despite not thinking about sex, most women have some degree of satisfaction during sex. Within this context, foreplay plays an important role, with $71 \%$ of women stating that usually, or always, foreplay encourages them to continue the intercourse.

Regarding the concept of personal arousal and attunement with the partner, addressed by questions 4 and 5 , most women never, rarely, or sometimes get lubricated during intercourse. Conversely, $71 \%$ of women reported that they are often or always aroused by the partner's excitement. Regarding comfort during sex, $80.7 \%$ of women responded they relax the vagina during penetration, and $51.7 \%$ have some degree of pain during sex. This fact is alarming, considering that the index of the general Brazilian population that refers to some degree of dyspareunia is $17.8 \%$. In this regard, it is worth mentioning that vaginal dryness is common in women treated for breast cancer ${ }^{10}$. This is due to the postmenopausal status faced by most women, either because of premature ovarian insufficiency resulting from systemic treatment, or because of their age at the time of diagnosis. Hormone replacement therapy is contraindicated for this population ${ }^{10}$. The treatment of choice for genitourinary symptoms in women with personal history of breast cancer consists in lubricants and pelvic floor physiotherapy. Topical hormone therapy can also be considered, depending on the cancer treatment the patient is currently undergoing. For women who do not respond to first-line therapy, and who choose not to use topical hormone therapy, the use of vaginal laser is an option ${ }^{10,11}$.

Finally, when assessing the phases of the sexual response cycle, $19.4 \%$ of women responded that they never reach orgasm during intercourse. In comparison with national data, this number is lower than the $26.2 \%$ of healthy women who reported the same fact. Conversely, $67.8 \%$ responded that the satisfaction with intercourse makes them desire to have sex on other days.
In a recent publication of the Journal of Clinical Oncology, psychosocial and/or psychosexual therapy is recommended for all cancer patients, aiming at improving sexual response, body image, intimacy and relationship issues, and the overall sexual function and satisfaction. First, factors contributing to cancer and treatable factors must be identified and addressed. In addition to the aforementioned treatments for genitourinary symptoms, both women and men with vasomotor symptoms should be cared for treating these symptoms, including behavioral options, such as cognitive behavioral therapy, slow breathing and hypnosis, and medications such as venlafaxine and gabapentin ${ }^{11}$. The latest meta-analysis published on the Cochrane platform, in 2016, on interventions in sexual dysfunction during cancer treatment in women included 1,509 women randomized in 11 trials. All studies investigated interventions after treatment for both gynecologic cancer and breast cancer. Eight studies evaluated a psychotherapeutic or psychopedagogical intervention. Two studies evaluated a pharmaceutical intervention and a pelvic floor exercise. All trials involved heterosexual women. In trials that evaluated a psychotherapeutic intervention, the effect on sexual dysfunction varied; in three studies, benefit for some measures of sexual function was reported; and in five studies, no benefit was found. The evidence on pharmaceutical interventions and pelvic floor exercise was inconclusive. Only the study on a pH-balanced vaginal gel found significant improvements in sexual function ${ }^{12}$.

In practical terms, the treatment of women with breast cancer and sexual dysfunction must follow a safe and reliable pattern. Behavioral and non-pharmacological measures are the ones chosen for initiating the approach: sex therapy, lubricants, vaginal moisturizers, self-stimulators (vibrators), vaginal dilators, and pelvic floor physiotherapy. In case these methods do not work, vaginal laser is a great option, with great results in the treatment of vaginal atrophy. Women with persistent and severe symptoms, who did not respond to nonhormonal treatments and who present factors that suggest a low risk of recurrence, may be candidates for local hormone therapy such as estradiol-based creams ${ }^{10}$. Understanding the approach and treatment of women is essential, considering that the prevalence of sexual dysfunction in this population is high, accounting for $73 \%^{3}$.

In this study there was no statistical correlation between the cancer treatments and sexual dysfunction. Hence, the authors believe that the absence of significant results was due to the small number of research participants (31 women). The literature corroborates this finding. A study published in 2019 included interviews with 278 sexually active women. Overall, 65\%, 27\%, and $8 \%$ underwent mastectomy, mastectomy with breast reconstruction, and simple mastectomy, respectively. In total, $74.5 \%$ reported undergoing radiotherapy; $47.8 \%$, chemotherapy; $27.3 \%$, use of tamoxifen; and $31.4 \%$, use of aromatase inhibitor (AI). 
There was no significant difference in the prevalence of sexual dysfunction per surgical modality, even when adjusted for adjuvant treatment. Chemotherapy or radiotherapy had no association with sexual dysfunction either. The only type of therapy that was correlated with sexual dysfunction was the use of AI, 1.6 times higher in the group who used the medication $(p=0.01)$. The researchers concluded that the highest rates of sexual dysfunction were among breast cancer survivors treated with AI. Surgical modality, chemotherapy, and radiotherapy were not associated with sexual dysfunction ${ }^{13}$.

The present study presents partial results from a sample of women treated for breast cancer. The results were not statistically significant, but these data are worth of attention, and new national studies should be encouraged. Sexual dysfunction affects most of the study patients, and mastologists must be prepared to address, identify, and treat this pathology that severely impairs the quality of life.

\section{CONCLUSION}

Most women treated for breast cancer had sexual performance classified as "good and excellent," although a significant percentage had a diagnosis of sexual dysfunction. Dyspareunia is the most prevalent symptom when compared with the population without breast cancer.

\section{AUTHORS' CONTRIBUTIONS}

LS: Investigation.

CV: Conceptualization.

VP: Methodology.

FN: Methodology.

FF: Investigation.

MM: Supervision.

Jj: Supervision.

DB: Supervision, Project administration.

\section{REFERENCES}

1. Soldera SV, Ennis M, Lohmann AE, Goodwin PJ. Sexual health in long-term breast cancer survivors Breast Cancer Res Treat. 2018;172(1):159-66. http://doi.org/10.1007/s10549-018-4894-8

2. Instituto Nacional de Câncer. Portal [Internet]. Rio de Janeiro: INCA [cited on Sept. 12, 2019]. Available from: http://www. inca.gov.br

3. Jing L, Zhang C, Li W, Jin F, Wang A. Incidence and severity of sexual dysfunction among women with breast cancer: a metaanalysis based on female sexual function index. Support Care Cancer. 2019;27(4):1171-80. http://doi.org/10.1007/s00520-01904667-7

4. Makluf ASD, Dias RC, Barra AA. Avaliação da qualidade de vida em mulheres com câncer da mama. Rev Bras Cancerol. 2006;52(1):49-58.

5. Sehati Shafaee F, Mirghafourvand M, Harischi S, Esfahani A, Amirzehni J. Self-Confidence and Quality of Life in Women Undergoing Treatment for Breast Cancer. Asian Pac J Cancer Prev. 2018;19(3):733-40. https://doi.org/10.22034/APJCP.2018.19.3.733

6. CoadyD,KennedyV.SexualHealthinWomenAffectedbyCancer: Focus on Sexual Pain. Obstet Gynecol. 2016;128(4):775-91. https://doi.org/10.1097/aog.0000000000001621

7. Panjari M, Bell RJ, Davis SR. Sexual function after breast cancer. J Sex Med. 2011;8(1):294-302. https://doi.org/10.1111/ j.1743-6109.2010.02034.x

8. Weinberger JM, Houman J, Caron AT, Anger J. Female Sexual Dysfunction: A Systematic Review of Outcomes Across
Various Treatment Modalities. Sex Med Rev. 2019;7(2):223-50. https://doi.org/10.1016/j.sxmr.2017.12.004

9. Abdo CHN. Quociente Sexual Feminino: Um Questionário Brasileiro para Avaliar a Atividade Sexual da Mulher. Diagn Tratamento. 2009;14(2):89-1.

10. Faubion SS, Larkin LC, Stuenkel CA, Bachmann GA, Chism LA, Kagan R, et al. Management of genitourinary syndrome of menopause in women with or at high risk for breast cancer: consensus recommendations from The North American Menopause Society and The International Society for the Study of Women's Sexual Health. Menopause. 2018;25(6):1-13. https://doi.org/10.1097/GME.0000000000001121

11. Carter J, Lacchetti C, Andersen BL, Barton DL, Bolte S, Damast S, et al. Interventions to Address Sexual Problems in People With Cancer: American Society of Clinical Oncology Clinical Practice Guideline Adaptation of Cancer Care Ontario Guideline. J Clin Oncol. 2018;36(5):492-511. https://doi. org/10.1200/jco.2017.75.8995

12. CandyB,Jones L,VickerstaffV,Tookman A, KingM.Interventions for sexual dysfunction following treatments for cancer in women. Cochrane Database Syst Rev. 2016;(2):CD005540. https://doi.org/10.1002/14651858.CD005540.pub3

13. Gandhi C, Butler E, Pesek S, Kwait R, Edmonson D, Raker C, et al. Sexual Dysfunction in Breast Cancer Survivors. Is it Surgical Modality or Adjuvant Therapy? Am J Clin Oncol. 2019;42(6):500-6. https://doi.org/10.1097/ coc.0000000000000552 
Appendix 1. Female Sexual Quotient (QS-F) questionnaire.

Answer this questionnaire with honesty, based on the last six months of your sex life, considering the following score:

$0=$ never

$1=$ rarely

2 = sometimes

$3=$ often 4 = usually

$5=$ always

1. Do you usually have spontaneous thoughts about sex, remember sex, or imagine yourself having sex?

( ) 0 ( ) 1 ( ) 2 ( ) 3 ( ) 4 ( ) 5

2. Are you interested enough in sex to willingly engage in intercourse?

( ) 0 ( ) 1 ( ) 2 ( ) 3 ( ) 4 ( ) 5

3. Does foreplay (caresses, kisses, hugs, cuddles, etc.) encourage you to continue intercourse?

( ) 0 ( ) 1 ( ) 2 ( ) 3 ( ) 4 ( ) 5

4. Do you usually get lubricated during intercourse?

( ) 0 ( ) 1 ( ) 2 ( ) 3 ( ) 4 ( ) 5

5. During intercourse, as your partner's arousal increases, do you feel more stimulated to have sex?

( ) 0 ( ) 1 ( ) 2 ( ) 3 ( ) 4 ( ) 5

6. During intercourse, do you relax the vagina enough to facilitate penile penetration?

( ) 0 ( ) 1 ( ) 2 ( ) 3 ( ) 4 ( ) 5

7. Do you usually feel pain during intercourse when the penis penetrates your vagina?

( ) 0 ( ) 1 ( ) 2 ( ) 3 ( ) 4 ( ) 5

8. Can you be engaged, without getting distracted (without losing concentration), in and during intercourse?

( ) 0 ( ) 1 ( ) 2 ( ) 3 ( ) 4 ( ) 5

9. Can you reach orgasm (maximum pleasure) in the intercourses you engage in?

( ) 0 ( ) 1 ( ) 2 ( ) 3 ( ) 4 ( ) 5

10. Does the degree of satisfaction you feel from intercourse make you desire to have sex at other times, on other days? ( ) 0 ( ) 1 ( ) 2 ( ) 3 ( ) 4 ( ) 5

Answer key

Result = sexual performance pattern:

\begin{tabular}{|l|l|}
\hline 82-100 points & Good to excellent \\
\hline 62-80 points & Regular to good \\
\hline $42-60$ points & Unfavorable to regular \\
\hline $22-40$ points & Bad to unfavorable \\
\hline $0-20$ points & Null to bad \\
\hline
\end{tabular}

How to get the result:

Add the points assigned to each question, subtract 5 points from question 7, and multiply the total by 2:

$2 \times(\mathrm{Q} 1+\mathrm{Q} 2+\mathrm{Q} 3+\mathrm{Q} 4+\mathrm{Q} 5+\mathrm{Q} 6+[5-\mathrm{Q} 7]+\mathrm{Q} 8+\mathrm{Q} 9+\mathrm{Q} 10)$

(Q = question)

[5-Q 7] = Question 7 requires this subtraction to be previously done and the result to be included in the sum of the questions. 